\title{
siRNA targeting survivin inhibits the growth and enhances the chemosensitivity of hepatocellular carcinoma cells
}

\author{
WENSONG LIU ${ }^{1}$, FENG ZHU ${ }^{1}$, YONG JIANG ${ }^{1}$, DONGLIN SUN ${ }^{1}$, BO YANG ${ }^{1}$ and HAIJIAO YAN ${ }^{2}$ \\ Departments of ${ }^{1}$ Hepatobiliary Surgery, and ${ }^{2}$ Oncology, The Third Affiliated Hospital \\ of Soochow University, Changzhou, Jiangsu 213003, P.R. China
}

Received September 6, 2012; Accepted November 16, 2012

DOI: $10.3892 /$ or.2012.2196

\begin{abstract}
Survivin has become an attractive anticancer therapeutic target due to its important role in tumor cell viability and its selective expression in tumor cells. In the present study, we constructed a recombinant siRNA plasmid vector against survivin and stably transfected it into HepG2 and SMMC-7721 hepatocellular carcinoma cells in vitro. Semi-quantitative RT-PCR and western blotting were used to determine the expression of survivin mRNA and protein, respectively. Tumor cell proliferation was assessed by trypan blue exclusion. We evaluated the change in caspase-3 activity, and the rate of cell apoptosis and the cell cycle distribution were analyzed by flow cytometry. Assessment of chemosensitivity was carried out by MTT assay. The results showed that transfection of survivin siRNA caused a significant inhibition of survivin mRNA and protein expression which was associated with cell growth inhibition, specific G0/G1 phase arrest, increased caspase- 3 activity and enhanced chemosensitivity to cisplatin in both HCC cell lines. We suggest that suppression of survivin expression by RNAi attenuates the malignant phenotype of hepatocellular carcinoma cells, and may provide a novel approach for anticancer gene therapy.
\end{abstract}

\section{Introduction}

Hepatocellular carcinoma (HCC) is one of the most prevalent and lethal human malignancies, and it causes approximately half a million deaths each year worldwide (1). Although curative treatments such as hepatic resection, percutaneous regional treatments, and even liver transplantation are available for HCC, it still has a high frequency of postoperative recurrence and poor prognosis $(2,3)$. To date, there is no proven effective systemic chemotherapy for HCC due to the

Correspondence to: Dr Haijiao Yan, Department of Oncology, The Third Affiliated Hospital of Soochow University, Juqian Road 185, Changzhou, Jiangsu 213003, P.R. China

E-mail: haijiao8237@163.com

Key words: survivin, RNA interference, hepatocellular carcinoma, chemosensitivity resistance of tumor cells to cytotoxic drugs $(4,5)$. The efficacy of local chemotherapy, using agents such as cisplatin by means of transarterial chemoembolization, is limited due to the poor response rate of tumor cells to treatment and tumor re-growth after treatment (6). These reasons exemplify the need to fully understand the mechanism underlying chemoresistance in $\mathrm{HCC}$ to allow the design of more effective therapeutic strategies.

Survivin has recently been identified as the smallest member of the inhibitor of apoptosis protein (IAP) family, which counteracts apoptosis and regulates cell division (7). Survivin is expressed in embryonic tissues as well as in the majority of types of human cancers, but is undetectable in most terminally differentiated normal adult tissues $(8,9)$. High levels of survivin expression are associated with cancer progression, decreased survival time and poor prognosis, which make survivin a promising target for anticancer therapies (10). It has been reported that survivin promotes cell proliferation in human HCC both in vitro and in vivo (11). Survivin is also reported to be involved in cancer cell resistance to radiation therapy, as well as to chemotherapy $(12,13)$. Previous studies have demonstrated that the inhibition of survivin expression by RNAi inhibits the tumor growth of HCC cells in vitro and in vivo (14). However, whether the suppression of survivin enhances the chemosensitivity of HCC cells to cisplatin has not been investigated until now.

In the present study, we constructed the siRNA plasmid expression vector targeting survivin and stably transfected it into HepG2 and SMMC-7721 HCC cells. Then changes in survivin expression and the role of siRNA in inducing cancer cell apoptosis and enhancing chemosensitivity to cisplatin were investigated. The present research provides a foundation for further study on survivin siRNA gene therapy for human hepatocellular carcinoma.

\section{Materials and methods}

Cell lines and cell culture. Human hepatocellular carcinoma cell lines HepG2 and SMMC-7721 were provided by Culture Central of Wuhan University (Wuhan, China). They were maintained in DMEM culture medium, supplemented with $10 \%$ fetal bovine serum at $37^{\circ} \mathrm{C}$ in a humidified atmosphere containing $5 \% \mathrm{CO}_{2}$, fed with fresh medium every 3 days and subcultured when confluency was reached. 
Construction and transfection of the siRNA plasmid expression vector. Based on the human survivin gene sequence (GenBank no. NM_001168), we designed the survivin siRNA targeting against the sequence, 5'-ACCGCATCTCTACATTC AAGA-3', while the negative control siRNA targeted the sequence, 5'-GACCTACCACTCACGATTAAT-3'. Short hairpin primers were designed around these sequences and annealed before their ligation into the $B b s I$ sites of the psiRNA-hH1neo plasmid (Invivogen). The survivin-targeted and the negative control nucleotide sequences were both confirmed against the Genbank database to prevent any improper interaction on other mRNA transcripts. The recombinant plasmids were designated as psiRNA-sur and psiRNA-con and confirmed by enzyme cutting and sequencing.

When cells were $70-80 \%$ confluent, transfection was performed following the manufacturer's protocol. In brief, HepG2 and SMMC-7721 cells were co-transfected with $1 \mu \mathrm{g}$ of plasmid and $3 \mu \mathrm{l}$ of Lipofectamine (Invitrogen), respectively. The medium was replaced with fresh complete medium $6 \mathrm{~h}$ after transfection. Then cells were selected with $500 \mu \mathrm{g} /$ $\mathrm{ml}$ of G418 for 2 weeks. The resulting resistant clones were isolated and maintained with $200 \mu \mathrm{g} / \mathrm{ml}$ of G418.

Semi-quantitative RT-PCR. The total RNA of the untransfected HCC cells and the psiRNA-sur or psiRNA-con stably transfected cells was extracted with TRIzol reagent (Invitrogen) according to the manufacturer's instructions. The RNA of each group $(1 \mu \mathrm{g})$ was used to synthesize cDNA, and the cDNA was added to a final volume of $25 \mu \mathrm{l}$, with $1 \mu \mathrm{l}$ of each primer. The primers for human survivin were 5'-CTCAAGGACCACC GCATCT-3' (forward) and 5'-AGCGCAACCGGACGAAT-3' (reverse). $\beta$-actin was used as an internal control, and its primers were 5'-CGGGAAATCGTGCGTGAC-3' (forward) and 5'-GATCTTCATTGTGCTGGGTG-3' (reverse). The RT-PCR products were electrophoresed on a $1.5 \%$ ethidium bromide-stained agarose gel, and densitometric analysis was performed using Scion Image software.

Western blot analysis. The total cellular protein extract for each cell group was obtained by lysing the cancer cells in lysis buffer. Western blot analysis was then performed following conventional protocols. An equal amounts of each protein sample $(20 \mu \mathrm{g})$ was electrophoresed on $12 \%$ sodium dodecyl sulfate-polyacrylamide gel (SDS-PAGE), and then transferred onto a PVDF membrane (Millipore). The PVDF membrane was blocked in PBS containing 5\% skimmed milk and incubated overnight with anti-survivin $(1: 1,000)$ and antiactin (1:2,000; Santa Cruz Biotechnology), and then incubated with secondary horseradish peroxidase-conjugated antibodies for $1 \mathrm{~h}$ at room temperature. After extensive rinsing, the blots were developed with a Luminol chemiluminescence detection kit (Santa Cruz Biotechnology). Band densities of the blots from photographic film were quantified using digital image analysis.

Detection of cell proliferation. For cell proliferation analysis, the stably transfected cells and untransfected HepG2 and SMMC-7721 cells were seeded in 6-well plates and cultured in the presence of $10 \%$ FBS for 8 days. Cells were harvested by trypsinization at various times and stained with trypan blue. Viable cells were counted using a hematocytometer and an inverted microscope. The cell numbers were averaged over 3 independent experiments.

Analysis of the cell cycle by flow cytometry. Stably transfected HepG2 and SMMC-7721 cells and untransfected cells were seeded in 6-well plates. When the cells were $~ 80 \%$ confluent, cells were collected and washed with cold PBS, and then fixed in $2 \mathrm{ml}$ of $70 \%$ ethanol and preserved at $4^{\circ} \mathrm{C}$. The fixed cells were washed three times, and resuspended in PBS containing $50 \mathrm{mg} / \mathrm{ml}$ of RNase A for $30 \mathrm{~min}$, and then incubated with $10 \mathrm{mg} / \mathrm{ml}$ propidium iodide (PI) for $20 \mathrm{~min}$ in the dark, and the cell cycle distribution was analyzed by flow cytometry (BD Biosciences).

Caspase-3 activity assay. The CaspACE ${ }^{\mathrm{TM}}$ Assay system kit (Promega) was used to measure the activity of caspase-3, according to the manufacturer's instructions (15). The groups of HCC cells were collected and washed with cold PBS, and the cell lysates were prepared. Assays were performed on 96-well plates. We added $2 \mu \mathrm{l}$ of the DEVD-pNA substrate (10 mM stock) to $20 \mu \mathrm{l}$ of the cell lysate (50 $\mu \mathrm{g}$ total protein) in each well, followed by incubation at $37^{\circ} \mathrm{C}$ for $4 \mathrm{~h}$. Absorbance was measured at $405 \mathrm{~nm}$ with an ELISA reader.

Analysis of apoptosis. We identified the effect of different concentrations of cisplatin on HepG2 cels proliferation by MTT assay, and selected a concentration of $10 \mu \mathrm{M}$ as the optimal low dose of cisplatin (16). Cells of each group were seeded into 6-well plate. When the cells were $\sim 70 \%$ confluent, $10 \mu \mathrm{M}$ of cisplatin was added to the cells (Sigma). After $48 \mathrm{~h}$, the cells were harvested and washed by PBS twice. Annexin V and PI staining were carried out using the Annexin V-FITC/PI kit (BD Biosciences), following the manufacturer's protocol. After incubation for $20 \mathrm{~min}$ at room temperature avoiding light, cell apoptosis was immediately detected by flow cytometry. All of the samples were assayed in triplicate.

Chemosensitivity assessment with MTT assays. Cells were plated in quadruplicate at a density of 5,000 cells/well in 96-well plates, and were allowed to adhere overnight. The cells were then treated with cisplatin at a concentration of $10 \mu \mathrm{M}$. After $48 \mathrm{~h}$ cells were washed with PBS, and MTT was added to each well at $50 \mu \mathrm{g} /$ well for $4 \mathrm{~h}$ and the produced formazan was solubilized for $15 \mathrm{~min}$ by DMSO. Absorbance was measured at $570 \mathrm{~nm}$ with a microplate reader. Cells treated with equivalent amounts of DMSO were used as controls.

Statistical analysis. SPSS 10.0 software was used to analyze the data, which were expressed as the means \pm SD. Statistical comparisons of numerical data within groups were carried out using one-way ANOVA test. A P-value of $<0.05$ was considered to indicate a statistically significant result.

\section{Results}

Suppression of survivin expression in HCC cells by RNAi. psiRNA-sur was transfected into HepG2 and SMMC-7721 cells and stable transfectants were obtained by G418 selection. To confirm that siRNA transfection downregulates survivin 


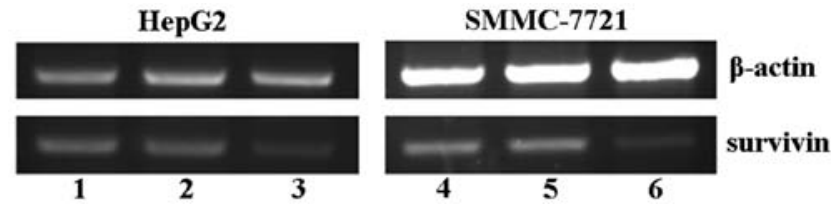

Figure 1. Suppression of survivin mRNA expression measured by semi-quantitive RT-PCR. Lane 1, HepG2; lane 2, HepG2 with control siRNA; lane 3, HepG2 with survivin siRNA; lane 4, SMMC-7721; lane 5, SMMC-7721 with control siRNA; line 6, SMMC-7721 with survivin siRNA. The inhibitory rates of survivin mRNA expression were $68.38 \pm 3.94$ and $70.43 \pm 3.53 \%$ in HepG2 and SMMC-7721 cells, respectively following transfection with survivin siRNA $(\mathrm{P}<0.05$, compared with untransfected and negative control cells).

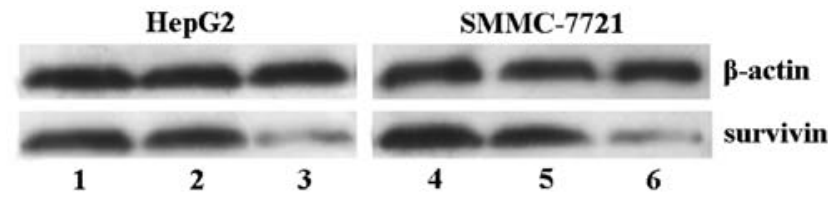

Figure 2. Suppression of survivin protein expression measured by western blot analysis. Lane 1, HepG2; lane 2, HepG2 with control siRNA; lane 3 , HepG2 with survivin siRNA; lane 4, SMMC-7721; lane 5, SMMC-7721 with control siRNA; lane 6, SMMC-7721 with survivin siRNA. The inhibitory rates of survivin protein expression were $75.35 \pm 4.08$ and $76.59 \pm 4.61 \%$ in HepG2 and SMMC-7721 cells, respectively by transfection with survivin siRNA $(\mathrm{P}<0.05$, compared with untransfected and negative control cells).
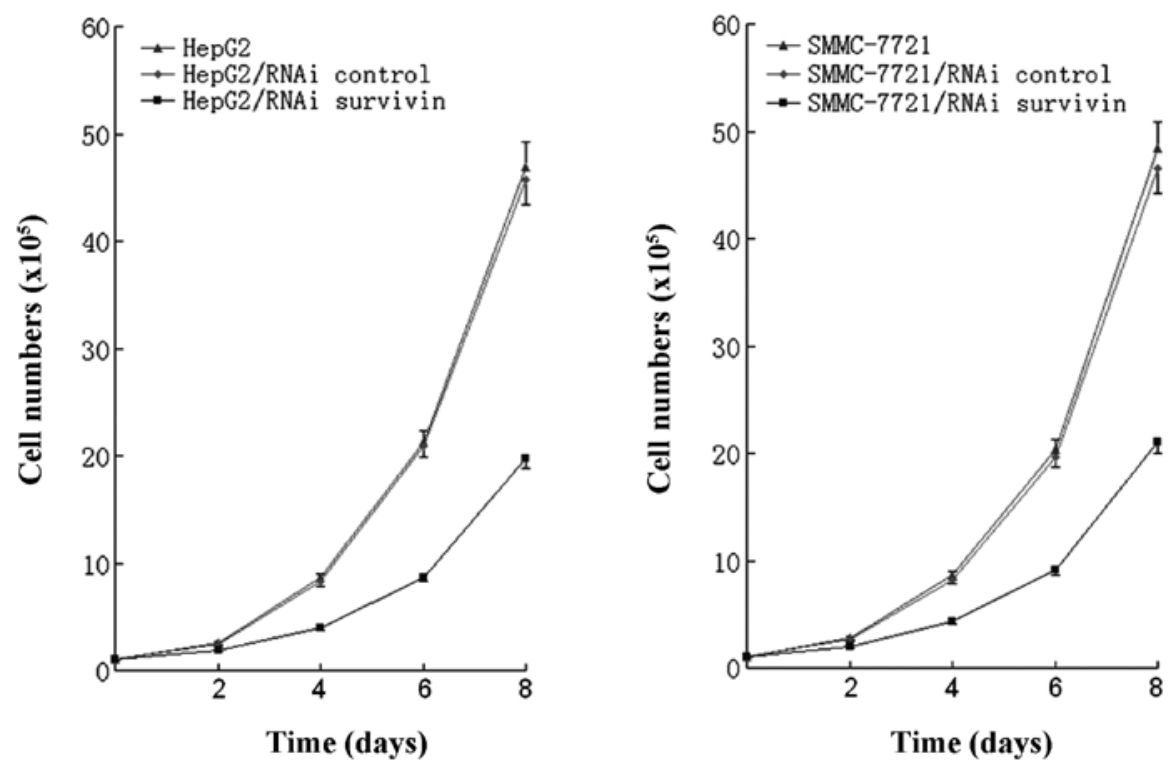

Figure 3. Cell growth curve. Cell growth was measured by the cell count, and the results showed a notable decrease in cell proliferation in a time-dependent manner following transfection with survivin siRNA compared with control cells. The highest inhibitory rate was $57.78 \pm 2.63$ and $56.40 \pm 3.02 \%$ for HepG2 and SMMC-7721 transfected with the survivin siRNA, respectively, on Day $8(\mathrm{P}<0.05)$.

expression in each cell line, RT-PCR assay and western blotting were performed. Survivin mRNA and protein were both strongly expressed in HepG2 and SMMC-7721 cells as reflected by semi-quantitative RT-PCR and western blotting. Our data showed that after stable transfection with survivin siRNA, the inhibition ratios of survivin mRNA and protein expression were $68.38 \pm 3.94$ and $75.35 \pm 4.08 \%$ in HepG2 cells, respectively, and $70.43 \pm 3.53$ and $76.59 \pm 4.61 \%$ in SMMC-7721 cells, respectively (Figs. 1 and 2$)(\mathrm{P}<0.05)$. Transfection with psiRNA-con did not alter survivin expression levels, indicating that the inhibitory effect of survivin siRNA was specific. In addition, siRNA did not cause non-specific downregulation of gene expression, as determined by the $\beta$-actin control. Together, these results proved that the vector based RNAi effectively and stably suppressed survivin expression in hepatocellular carcinoma cells.

Survivin siRNA significantly inhibits HCC cell growth. Overexpression of survivin has been reported in the majority of human cancers including HCC, but not in normal tissue. Thus, increased levels of survivin may play an important role in the growth advantage of HCC. Our data showed that siRNA targeting against survivin significantly decreased the growth rate of cancer cells in a time-dependent manner, and the highest inhibition rates of cell proliferation were $57.78 \pm 2.63$ and $56.40 \pm 3.02 \%$ for HepG2 and SMMC-7721 cells, respectively, on Day $8(\mathrm{P}<0.05)$ (Fig. 3). However, transfection with psiRNA-con did not alter the growth rate of cancer cells.

Alteration in the cell cycle by survivin siRNA. The cell cycle distribution of the HepG2 and SMMC-7721 cells was analyzed by flow cytometry after stable transfection by survivin siRNA. Our results showed that, compared with the untransfected HepG2 cells, psiRNA-survivin-transfected cells were arrested in the $\mathrm{G} 0 / \mathrm{G} 1$ phase $(64.52 \pm 3.08 \%)(\mathrm{P}<0.05)$ and the number of cells was reduced in the $\mathrm{G} 2 / \mathrm{M}$ phase $(8.98 \pm 0.52 \%)(\mathrm{P}<0.05)$. psiRNA-survivin-transfected SMMC-7721 cells were also arrested in the G0/G1 phase $(61.23 \pm 3.15 \%)(\mathrm{P}<0.05)$ and the number of cells was reduced in the $\mathrm{G} 2 / \mathrm{M}$ phase $(12.36 \pm 0.87 \%)$ $(\mathrm{P}<0.05)$ (Fig. 4, Table I).

Effect of survivin siRNA on the activity of caspase-3. We measured the enzymatic activity of caspase- 3 to investigate whether inhibition of survivin expression induces apoptosis 

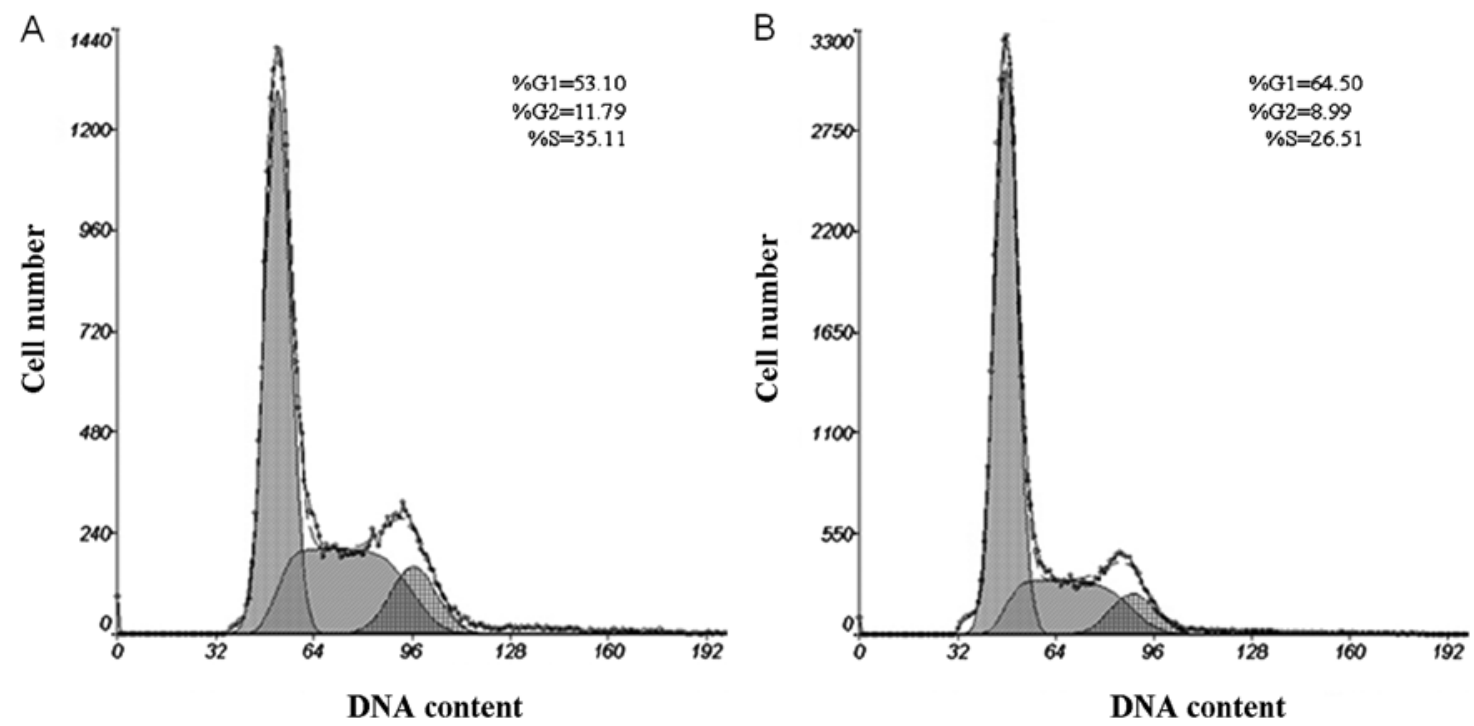

Figure 4. Analysis of the cell cycle distribution by flow cytometry. After stable transfection by survivin siRNA, HepG2 cells were obviously arrested in the G0/ G1 phase $(64.52 \pm 3.08 \% ; \mathrm{P}<0.05)$, and the number of cells was reduced in the $\mathrm{G} 2 / \mathrm{M}$ phase $(8.98 \pm 0.52 \% ; \mathrm{P}<0.05)$. (A) HepG2 cells; (B) HepG2 cells transfected with survivin siRNA.

Table I. Comparison of the cell cycle distribution following transfection of the cell lines with survivin siRNA(means \pm SD).

\begin{tabular}{lccr}
\hline Cells & G0/G1 $(\%)$ & S $(\%)$ & G2/M (\%) \\
\hline HepG2 & $53.10 \pm 2.92$ & $35.11 \pm 1.83$ & $11.79 \pm 0.84$ \\
HepG2/RNAi & $64.52 \pm 3.08$ & $26.50 \pm 1.55$ & $8.98 \pm 0.52$ \\
SMMC-7721 & $50.85 \pm 2.81$ & $29.95 \pm 1.89$ & $19.20 \pm 1.76$ \\
SMMC-7721/RNAi & $61.23 \pm 3.15$ & $26.41 \pm 1.72$ & $12.36 \pm 0.87$ \\
\hline
\end{tabular}

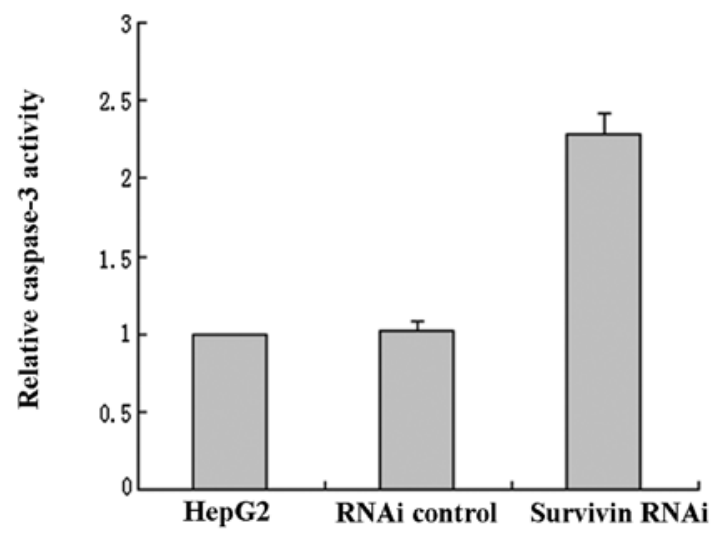

Figure 5. Effect of survivin siRNA on the activity of caspase-3 in HepG2 cells. The results showed that activity of caspase-3 in HepG2 cells was markedly increased by transfection with survivin siRNA ( $2.28 \pm 0.19$-fold; $\mathrm{P}<0.05$, compared with untransfected and negative control cells).

in HCC cells. The results showed that activity of caspase-3 in HepG2 cells was markedly increased by survivin-siRNA ( $2.28 \pm 0.19$-fold, $\mathrm{P}<0.05)$, while there was no difference between the blank control and the negative control cells (Fig. 5). The suppression of survivin expression significantly increased the caspase-3 activity in HepG2 cells, leading to cell apoptosis.
Suppression of survivin expression enhances cisplatin-induced cytotoxicity. When treated with cisplatin for $48 \mathrm{~h}$, the apoptosis rates in the untransfected HepG2 cells, negative control group, and the positive experimental group were $32.54 \pm 2.97$, $31.82 \pm 2.86$ and $51.25 \pm 3.53 \%$, respectively. The results were similar to that in the SMMC-7721 cells, which were $33.65 \pm 2.74,34.13 \pm 2.27$ and $54.58 \pm 3.81 \%$, respectively (Figs. 6 and 7). Additionally, following cisplatin chemotherapy for $48 \mathrm{~h}$, the MTT test showed that the inhibition rates of cell growth in the untransfected HepG2 cells, negative control group and positive experimental group were $35.53 \pm 2.79,36.27 \pm 2.95$ and $62.88 \pm 3.84 \%$, respectively, in HepG2 cells, and $37.76 \pm 2.65$, $38.21 \pm 2.58$ and $65.74 \pm 3.42 \%$, respectively, in the SMMC-7721 cells (Fig. 8). These results demonstrated that transfection with survivin siRNA combined with cisplatin treatment markedly enhanced cell apoptosis and cytotoxicity, suggesting that inhibition of survivin expression significantly enhances the chemosensitivity of hepatocellular carcinoma cells.

\section{Discussion}

Previous reports have demonstrated that survivin plays an important role in cancer proliferation and progression, by inhibiting apoptosis and facilitating mitosis, giving tumor cells a survival and growth advantage $(17,18)$. Survivin expression is also involved in tumor cell resistance to chemotherapy and radiotherapy (19). Since survivin is specifically overexpressed in most malignant tumors but not in most normal adult tissues, the inhibition of survivin has been pursued as a compelling strategy for cancer therapy (20).

Various strategies have been employed in order to knock down the overexpression of survivin in cancer cells, including dominant-negative mutation (21), antisense oligonucleotides (22) and anticancer vaccine (23). The recent emergence of siRNA technology as a powerful tool to specifically silence gene expression offers a new modality for anticancer therapeutics (24). RNAi is mediated by short interfering RNAs 

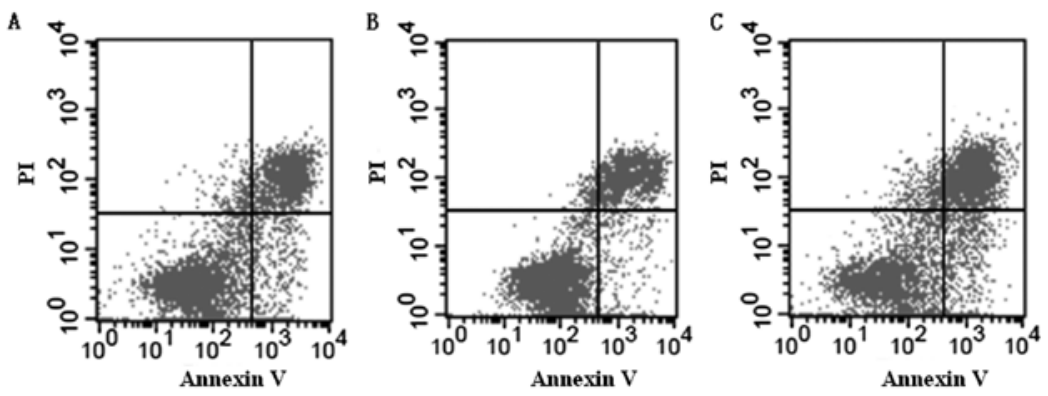

Figure 6. HepG2 cell apoptosis as measured by flow cytometry. (A) HepG2 cells + cisplatin; (B) HepG2 cells with control siRNA + cisplatin; (C) HepG2 cells with survivin siRNA + cisplatin. After treatment with cisplatin for $48 \mathrm{~h}$, the apoptosis rates in each cell group above were $32.54 \pm 2.97,31.82 \pm 2.86$ and $51.25 \pm 3.53 \%$, respectively.

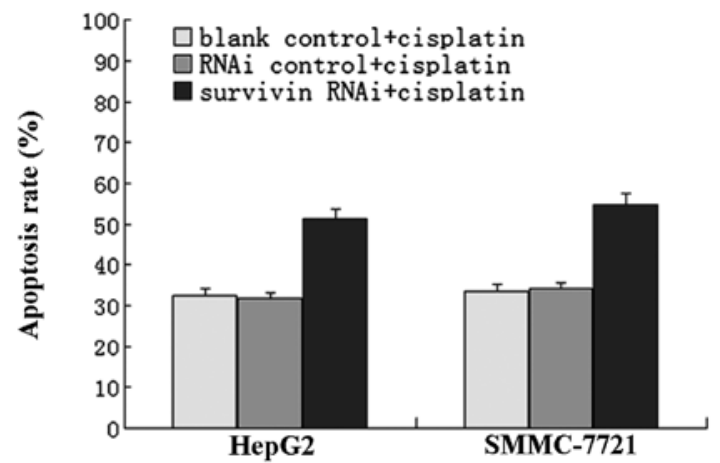

Figure 7. Cell apoptosis as detected by flow cytometry. Survivin siRNA significantly enhanced the apoptosis rate of HepG2 and SMMC-7721 cells to $51.25 \pm 3.53$ and $54.58 \pm 3.81 \%$, respectively after cisplatin chemotherapy ( $\mathrm{P}<0.05$, compared with untransfected and negative control cells).

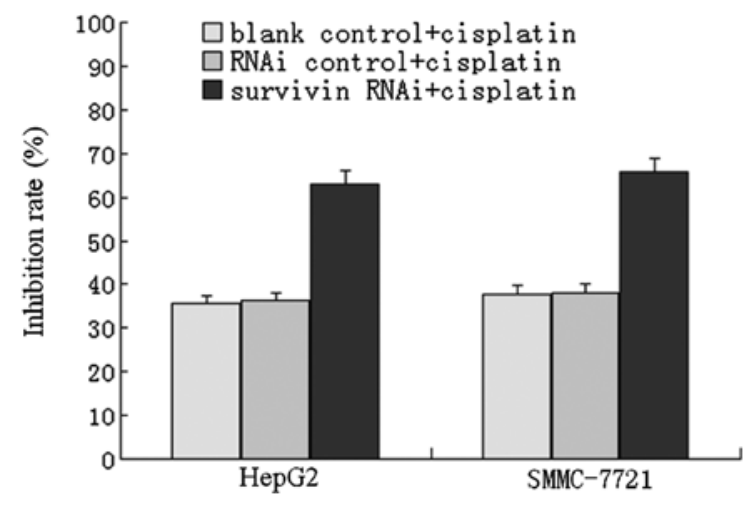

Figure 8. Cytotoxicity as measured by MTT. Following chemotherapy with cisplatin for $48 \mathrm{~h}$, transfection with survivin siRNA notably enhanced the inhibition rates of cell growth to $62.88 \pm 3.84$ and $65.74 \pm 3.42 \%$ in the HepG2 and SMMC-7721 cells, respectively $(\mathrm{P}<0.05$, compared with untransfected and negative control cells).

(siRNAs) that are produced from exogenous or endogenous long dsRNAs by Dicer endonuclease. The resulting siRNAs are then incorporated into a nuclease complex, which then cleaves corresponding mRNA in a sequence-specific manner $(25,26)$. RNAi has become a new technique for silencing gene expression, and plays an important role in gene function studies and in gene therapy for many diseases. In the present study, we successfully constructed recombinant siRNA plasmid expres- sion vector psiRNA-sur and stably transfected the plasmid into hepatocellular carcinoma HepG2 and SMMC-7721 cells. Semi-quantitative RT-PCR and western blotting demonstrated that survivin mRNA and protein expression levels were significantly reduced by over $60 \%$ when transfected with the siRNA targeting survivin in each cell line.

Survivin is the smallest member of the inhibitors of the apoptosis protein (IAP) family, and is the most powerful apoptosis inhibitory factor as far as we know. Survivin is a bifunctional protein, which has been involved in both control of apoptosis and regulation of cell division. It was demonstrated that survivin can directly bind to terminal effector caspase-3 and caspase-7, and suppresses apoptosis by the inhibition of caspase activities (27). Survivin inhibits the apoptosis pathway differently from Bcl-2, which blocks mitochondrial cytochrome c release into the cytosol, resulting in the inhibition of the mitochondrial apoptotic pathway. Overexpression of survivin may also overcome the $\mathrm{G} 2 / \mathrm{M}$ phase checkpoint to enforce progression of cells through mitosis (28). Survivin expression in hepatocellular carcinoma is reported to be corelated with proliferation, metastasis and prognosis $(29,30)$. In the present study, we found that the growth rates of the HepG2 and SMMC-7721 cell lines were inhibited by survivin siRNA. In addition, survivin siRNA induced a specific G0/ G1 arrest. Moreover, we found that the caspase-3 activity in both cell lines was significantly increased by survivin siRNA, which demonstrated that inhibition of survivin expression induced cell apoptosis. These results are important since they revealed the role of survivin in the development of hepatocellular carcinoma. Chen and Deng (31) also reported that siRNA targeting of survivin effectively inhibited the growth of gastric cancer MGC-803 cells.

To further investigate the role of survivin in the chemoresistance of hepatocellular carcinoma, we compared the changes in the chemosensitivity to cisplatin in the survivin siRNA-transfected and untransfected HCC cells. Our data showed that following cisplatin chemotherapy, survivin siRNA significantly enhanced cell apoptosis and the cytotoxicity of both HepG2 and SMMC-7721 cells in vitro, indicating that inhibition of survivin expression by siRNA significantly enhances the chemosensitivity of hepatocellular carcinoma cells. Our results are consistent with another report that inhibition of survivin expression enhances cisplatin sensitivity in squamous cell carcinoma of the tongue (32). 
In summary, hepatocellular carcinoma HepG2 and SMMC-7721 cells transfected with survivin siRNA showed decreased proliferation, increased apoptosis and caspase-3 activity, and increased chemosensitivity to cisplatin. Our data provide strong evidence that suppession of survivin expression by siRNA attenuates the malignant phenotype of HCC, and may provide a novel approach for anticancer gene therapy.

\section{Acknowledgements}

This study was supported by the National Natural Science Foundation of China (81201676), and the Young Talent Program of Science and Technology from the Changzhou Municipal Health Bureau (QN201103).

\section{References}

1. Mann CD, Neal CP, Garcea G, Manson MM, Dennison AR and Berry DP: Prognostic molecular markers in hepatocellular carcinoma: a systematic review. Eur J Cancer 43: 979-992, 2007.

2. Sakae M, Kubo S, Takemura S, Sakata C, Uenishi T, Kodai S, Shinkawa H, Urata Y, Ohata K, Kaneda K, Nishioka T, Nozawa A and Suehiro S: Effect of interferon therapy on first and second recurrence after resection of hepatitis c virus-related hepatocellular carcinoma. Hepatol Res 42: 564-573, 2012.

3. Fuks D, Dokmak S, Paradis V, Diouf M, Durand F and Belghiti J: Benefit of initial resection of hepatocellular carcinoma followed by transplantation in case of recurrence: an intention-to-treat analysis. Hepatology 55: 132-140, 2012.

4. Barbare JC, Bouche O, Bonnetain F, Raoul JL, Rougier P, Abergel A, Boige V, Denis B, Blanchi A, Pariente A, Milan C and Bedenne L: Randomized controlled trial of tamoxifen in advanced hepatocellular carcinoma. J Clin Oncol 23: 4338-4346, 2005.

5 Cabrera R and Nelson DR: Review article: the management of hepatocellular carcinoma. Aliment Pharmacol Ther 31: 461-476, 2010.

6. Kawaoka T, Aikata H, Takaki S, Katamura Y, Hiramatsu A, Waki K, Takahashi S, Hieda M, Toyota N, Ito K and Chayama K Transarterial infusion chemotherapy using cisplatin-lipiodol suspension with or without embolization for unresectable hepatocellular carcinoma. Cardiovasc Intervent Radiol 32: 687-694, 2009.

7. Wheatley SP and McNeish IA: Survivin: a protein with dual roles in mitosis and apoptosis. Int Rev Cytol 247: 35-88, 2005.

8. Liu J, Du W and Fan D: Survivin, the promising target in hepatocellular carcinoma gene therapy. Cancer Biol Ther 7: 555-556, 2008

9. Baykara M, Akkus M, Yildiz R, Gonul II, Dursun A, Coskun U, Benekli M, Sevinc A, Dane F and Buyukberber S: Survivin expression and its potential clinical significance in gastrointestinal stromal sarcoma. Int Immunopharmacol 11: 2227-2231, 2011.

10. Rodel F, Hoffmann J, Distel L, Herrmann M, Noisternig T, Papadopoulos T, Sauer R and Rodel C: Survivin as a radioresistance factor, and prognostic and therapeutic target for radiotherapy in rectal cancer. Cancer Res 65: 4881-4887, 2005.

11. Ito T, Shiraki K, Sugimoto K, Yamanaka T, Fujikawa K, Ito M, Takase K, Moriyama M, Kawano H, Hayashida M, Nakano T and Suzuki A: Survivin promotes cell proliferation in human hepatocellular carcinoma. Hepatology 31: 1080-1085, 2000.

12. Liu WS, Yan HJ, Qin RY, Tian R, Wang M, Jiang JX, Shen M and Shi CJ: siRNA directed against survivin enhances pancreatic cancer cell gemcitabine chemosensitivity. Dig Dis Sci 54: 89-96, 2009.
13. Kami K, Doi R, Koizumi M, Toyoda E, Mori T, Ito D, Kawaguchi Y, Fujimoto K, Wada M, Miyatake S and Imamura M: Downregulation of survivin by siRNA diminishes radioresistance of pancreatic cancer cells. Surgery 138: 299-305, 2005.

14. Zhang R, Ma L, Zheng M, Ren J, Wang T, Meng Y, Zhao J, Jia L, Yao L, Han H, Li K and Yang A: Survivin knockdown by short hairpin RNA abrogates the growth of human hepatocellular carcinoma xenografts in nude mice. Cancer Gene Ther 17: 275-288, 2010.

15. Zhang Y, Chen ZD, Du CJ, Xu G and Luo W: siRNA targeting survivin inhibits growth and induces apoptosis in human renal clear cell carcinoma 786-O cells. Pathol Res Pract 205: 823-827, 2009.

16. Guo X, Wang W, Zhou F, Lu Z, Fang R, Jia F, Bu X, Li R, Zhang B, Wu M and Wei L: siRNA-mediated inhibition of hTERT enhances chemosensitivity of hepatocellular carcinoma. Cancer Biol Ther 7: 1555-1560, 2008.

17. Altieri DC: New wirings in the survivin networks. Oncogene 27: 6276-6284, 2008.

18. Mita AC, Mita MM, Nawrocki ST and Giles FJ: Survivin: key regulator of mitosis and apoptosis and novel target for cancer therapeutics. Clin Cancer Res 14: 5000-5005, 2008.

19. Zhao W, Bao P, Qi H and You H: Resveratrol down-regulates survivin and induces apoptosis in human multidrug-resistant SPC-A-1/CDDP cells. Oncol Rep 23: 279-286, 2010.

20. Ryan BM, O'Donovan N and Duffy MJ: Survivin: a new target for anti-cancer therapy. Cancer Treat Rev 35: 553-562, 2009.

21. Yuan QZ, Wang CT, Mao YQ, Zhang P, Shi HS, Li ZY, Pan L, Yu DD, Leng F, Chen X, Ying W, Xu JH, Li W, Wu F, Wen Y, Ma TT and Wei YQ: Enhanced tumor radiosensitivity by a survivin dominant-negative mutant. Oncol Rep 23: 97-103, 2010.

22. Dai D, Liang Y, Xie Z, Fu J, Zhang Y and Zhang Z: Survivin deficiency induces apoptosis and cell cycle arrest in HepG2 hepatocellular carcinoma cells. Oncol Rep 27: 621-627, 2012.

23. Yang Z, Wang L, Wang H, Shang X, Niu W, Li J and Wu Y: A novel mimovirus vaccine containing survivin epitope with adjuvant IL-15 induces long-lasting cellular immunity and high antitumor efficiency. Mol Immunol 45: 1674-1681, 2008.

24. Couzin J: Breakthrough of the year. Small RNAs make big splash. Science 298: 2296-2297, 2002.

25 Klenov MS and Gvozdev VA: Heterochromatin formation: role of short RNAs and DNA methylation. Biochemistry 70: 1187-1198, 2005.

26. Nakahara K and Carthew RW: Expanding roles for miRNAs and siRNAs in cell regulation. Curr Opin Cell Biol 16: 127-133, 2004.

27. Nassar A, Lawson D, Cotsonis G and Cohen C: Survivin and caspase-3 expression in breast cancer: correlation with prognostic parameters, proliferation, angiogenesis, and outcome. Appl Immunohistochem Mol Morphol 16: 113-120, 2008.

28. Chiou SK, Jones MK and Tarnawski AS: Survivin - an antiapoptosis protein: its biological roles and implications for cancer and beyond. Med Sci Monit 9: PI25-PI29, 2003.

29. Fields AC, Cotsonis G, Sexton D, Santoianni R and Cohen C: Survivin expression in hepatocellular carcinoma: correlation with proliferation, prognostic parameters, and outcome. Mod Pathol 17: 1378-1385, 2004.

30. Zhu H, Chen XP, Zhang WG, Luo SF and Zhang BX: Expression and significance of new inhibitor of apoptosis protein survivin in hepatocellular carcinoma. World J Gastroenterol 11: 3855-3859, 2005.

31. Chen $\mathrm{T}$ and Deng C: Inhibitory effect of siRNA targeting survivin in gastric cancer MGC-803 cells. Int Immunopharmacol 8: 1006-1011, 2008.

32. Xu JH, Wang AX, Huang HZ, Wang JG, Pan CB and Zhang B: Survivin siRNA induces caspase-3-dependent apoptosis and enhances cisplatin sensitivity in squamous cell carcinoma of the tongue. Oncol Res 18: 377-385, 2010. 